REGULAR ARTICLE

\title{
IMPACT OF HIGH YIELDING WHEAT VARIETIES ON FARM INCOME OF SMALLHOLDER FARMERS IN ETHIOPIA
}

\author{
Regasa DIBABA ${ }^{1 *}$, Degye GOSHU ${ }^{2}$
}

\author{
Address: \\ ${ }^{1}$ Ethiopian Institute of Agricultural Research, Assosa Agricultural Research Center, Assosa, Ethiopia \\ ${ }^{2}$ Department of Agricultural Economics, Haramaya University, Dire Dawa, Ethiopia \\ Corresponding Author's e-mail: regasadibaba@yahoo.com
}

\begin{abstract}
The objective of this study was to estimate the impact of high yielding wheat varieties adoption on farm income of smallholders in Ethiopia. The study used cross-sectional data collected from 174 sample farm households selected through two-stage stratified random sampling techniques. Propensity score matching (PSM) applied to analyse the impact of adoption on farm income by smallholder farmers. The result of the PSM estimation showed that adoption of high yielding wheat varieties has significant impact on farm income of treated households as compared to the control groups. The treated households had earned farm income of about 21452 Ethiopian Birr per year while the untreated smallholders earned farm income of only 11141 Ethiopian Birr. The average treatment effect on the treated (ATT) of farm income of adopters is greater than non-adopters that has brought about $9 \%$ increase in farm income of smallholders. The findings suggest that the government and stakeholders would need to focus on further support of high yielding wheat varieties adoption and should be given due attention for its impact on farm income generation of smallholders.
\end{abstract}

Keywords: High yielding wheat varieties, Impact, Smallholder, PSM

JEL: C31, O13, O32, Q16

\section{INTRODUCTION}

In Ethiopia, agriculture takes the lion's share which is contributing about $72.7 \%$ in terms of employment. It is the source of food and cash for those who are engaged in the sector. Most agricultural holders acquire the food they consume and the cash they need to cover other expenses only from farming activities. Since farming in Ethiopia is often precarious and usually at the mercy of nature, it is invariably an arduous struggle for the smallholders to make ends meet (UNDP, 2014).

To feed the rapidly growing population and meet the high demand of wheat in the country, it needs to increase the production and yield of wheat. However, increasing yield requires successful adoption of improved agricultural technologies (Dorosh and Rashid, 2013). For this reason technological change is commonly considered as one of the major options leading to successful productivity growth in agriculture. In response to this, the intervention of high yielding wheat varieties widely undertaken in the area for years. Kathleen (2010) reported on his study that a well-designed impact assessment study can provide insight in to the causal factors behind the success and failure of various improved variety adoption activities. Impact assessment thus provides information that allows research and extension institutions to improve their services, and improve the welfare of the farmer.

Finally, there was no empirical information so far in the study area on the impact of high yielding wheat varieties adoption on the farm income of smallholders. Therefore, the study was proposed to estimate impact of high yielding wheat varieties on farm income of smallholder farmers and attempts to fill the gap of information on effect of high yielding wheat varieties adoption. The findings of this study could contribute to the growing body of literature and could also be used as a reference material for future researchers with areas having similar environments. Accordingly, this study would try to address the question that does high yielding wheat varieties adopted by smallholder farmers have impact on their farm income? It was particularly expected to address the impact of high yielding wheat varieties adoption on farm income of smallholder farmers.

\section{DATA AND METHODS}

\section{Description of Study Area}

Mao-Komo Special district is one of the 20 districts found in the Benishangul-Gumuz Regional State and located around $661 \mathrm{~km}$ away from Addis Ababa at the Western part of Ethiopia. The altitude of the district ranges from 950-1960 m.a.s.l. The temperature of the area ranges from 17.5-32 ${ }^{\circ} \mathrm{C}$. The rainfall of the district is uni-modal which starts in the month of April and ends in mid-October. The annual rainfall ranges from $900-1800 \mathrm{~mm}$ with mean annual rainfall is $1316 \mathrm{~mm}$, mostly received between May and September with the highest in July and August. The duration is about 6 to 7 months with good amount of rainfall distribution. Having an area of about $2100 \mathrm{Km}^{2}$ and population of about 42,050 (CSA, 2007). Farming is the predominant occupation of the people in the area since it is the main economic stay of the district.

\section{Data Types and Methods of Data Collection}

The study considers both primary and secondary sources of data. The primary data were collected from field 
observation and interviewing participants and nonparticipants of high yielding wheat varieties on data related to technologies. A semi-structured questionnaire was used to capture both qualitative and quantitative information. Secondary data were collected from literatures/articles, and reports of different organizations.

\section{Sampling Procedure}

The data used in this study comes from a household survey carried out. The study used a two stage stratified random sampling method. In the first stage, rural kebele administrations were stratified into two categories as potential and less potential wheat growers. Accordingly, three potential wheat producing kebeles were randomly selected. In the second stage, members of each kebele were stratified into two groups based on their adoption status of high yielding wheat varieties. Accordingly, a total of 174 farmers were randomly sampled taking into account probability proportional to size of households in each kebele for both groups.

\section{Methods of Data Analysis}

The study undertaken on the impact of high yielding wheat varieties adoption on farm income by smallholder farmers was evaluated by statistical tools and econometric models for concluding effect of adopting high yielding wheat varieties on smallholder farmers in the study area.

In this study, the econometric analysis that was employed propensity score matching techniques for evaluating the impact of high yielding wheat varieties adoption on farm income on the smallholders.

The propensity score matching (PSM) method, which was developed by Rosenbaum and Rubin (1983), has been extensively used in economics since 1990s to solve the matching problem. Rosenbaum and Rubin (1983) defined 'propensity score' as the conditional probability of receiving a treatment given pre-treatment characteristics:

$\mathrm{P}(\mathrm{X}) \equiv \operatorname{Pr}\{\mathrm{D}=1 \mid \mathrm{X}\}=\mathrm{E}\{\mathrm{D} \mid \mathrm{X}\}$

where: $\mathrm{D}=\{0,1\}$ is the indicator of exposure to treatment and $\mathrm{X}$ is the multidimensional vector of pre-treatment characteristics.

PSM constructs a statistical comparison group that is based on a model of the probability of participating in the treatment $T$ conditional on observed characteristics $X$, or the propensity score:

$$
P(X)=\operatorname{Pr}(T=1 \mid X)
$$

Rosenbaum and Rubin (1983) show that under certain assumptions, matching on $\mathrm{P}(\mathrm{X})$ is as good as matching on $X$. It applies for all situations where one has a treatment, a group of treated individuals and a group of untreated individuals, i.e. in this case adopters and nonadopters of high yielding wheat varieties. The nature of treatment might be very diverse (Caliendo and Kopeinig, 2008).

The propensity score matching approach tries to capture the effects of different observed covariates $X$ on participation in a single propensity score or index. Then, outcomes of participating and non-participating households with similar propensity scores are compared to obtain the program effect. Households for which no match is found are dropped because no basis exists for comparison (Khandker, 2010). With matching methods, one tries to develop a counterfactual or control group that is as similar to the treatment group as possible in terms of observed characteristics. The idea is to find, from a large group of non-participants, individuals who are observationally similar to participants in terms of characteristics not affected by the program. Each participant is matched with an observationally similar nonparticipant, and then the average difference in outcome across the two groups is compared to get the program treatment effect.

The study was employed 'with and without comparisons that compares' the behaviour in the key variables in a sample of program beneficiaries, with their behaviour in non-program takings (a comparison group) to assess the impact of high yielding varieties of wheat by households' on farm income. This is an approach to the counterfactual question, using the experiences of the comparison group as a proxy for what would otherwise have happened in the treatment beneficiaries. The aim of matching is to find the closest comparison group from a sample of non-participants to the sample of program participants. "Closest" is measured in terms of observable characteristics not affected by program participation. According to Christopher (2013) the impact of a treatment on individual $i$, is the difference between potential outcomes with and without treatment in estimating the effect of household's participation in the farm income for high yielding varieties of wheat due to adoption interventions being given outcome is specified as Eq. 3.

$\delta_{i}=Y_{1 i}-Y_{0 i}$

Where: $Y_{1}$ outcome of treatment (farm income of household, when he/she uses HYV of wheat);

$Y_{0}$ outcome of untreated individuals (farm income when he/she does not involve in HYV of wheat);

$\delta_{i}$ change in outcome as a result of treatment or change of income for participating in the program.

To evaluate the impact of a program over the population, we might be computed the average treatment effect (ATE). The average treatment effect (ATE) could be computed as follows (Eq. 4).

$\mathrm{ATE}=\mathrm{E}\left[\delta_{i}\right]=\mathrm{E}\left(\mathrm{Y}_{1}-\mathrm{Y}_{0}\right)$

Most often, we were interested in computing the average treatment effect on the treated (ATT) (Eq. 5).

$\mathrm{ATT}=\mathrm{E}\left(\mathrm{Y}_{1}-\mathrm{Y}_{0} \mid \mathrm{D}=1\right)$

where: $\mathrm{D}=1$ refers to the treatment.

The problem is that not all of these parameters are observable, as they rely on counterfactual outcomes. For instance, we could rewrite ATT as Eq. 6.

$\mathrm{ATT}=\mathrm{E}\left(\mathrm{Y}_{1} \mid \mathrm{D}=1\right)-\mathrm{E}\left(\mathrm{Y}_{0} \mid \mathrm{D}=1\right)$

The second term is the average outcome of treated 
individuals had they not received the treatment. We couldn't observe that, but we do observe a corresponding quantity for the untreated, and could be computed given the assumption the PSM estimator of ATT (Eq. 7).

$\mathrm{ATT}=\mathrm{E}\left(\mathrm{Y}_{1}-\mathrm{Y}_{0} \mid \mathrm{D}=0, \mathrm{p}(\mathrm{X})\right)=\mathrm{E}\left(\mathrm{Y}_{1} \mid \mathrm{D}=1, \mathrm{p}(\mathrm{X})\right)-\mathrm{E}$ $\left(\mathrm{Y}_{0} \mid \mathrm{D}=0, \mathrm{p}(\mathrm{X})\right)$

where: $\mathrm{p}(\mathrm{x})$ is the propensity score computed on the covariates;

$\mathrm{X}$ is explained as: the mean difference in outcomes over the common support, appropriately weighted by the propensity score distribution of participants.

According to Caliendo and Kopeinig (2008), there are steps in implementing PSM. These are estimation of the propensity scores using binary model, choosing a matching algorism, checking on common support condition, testing the matching quality (Eq. 8).

$$
\Delta=\mathrm{E}\left(\mathrm{Y}_{1} \mid \mathrm{D}=1\right)-\mathrm{E}\left(\mathrm{Y}_{0} \mid \mathrm{D}=0\right)
$$

The difference between ATT and $\Delta$ could be defined as Eq. 9:

$\Delta=\mathrm{ATT}+\mathrm{SB}$

where: SB is the selection bias term: the difference between the counterfactual for treated units and observed outcomes for untreated units. For the computable quantity $\Delta$ to be useful, the SB term must be zero.

The validity of the outputs of the PSM method depends on the satisfaction of two basic assumptions: the conditional independence assumption and the common support condition (Becker and Ichino, 2002). Conditional independence assumption (known as unconfoundedness assumption) states that the potential outcomes are independent of the treatment status, given X. The conditional independence assumption is crucial for correctly identifying the impact of the program since it ensures that, although treated and untreated groups differ, these differences might be accounted for in order to reduce the selection bias. This allows the untreated units to be used to construct a counterfactual for the treatment group. There exists a set $\mathrm{X}$ of observable covariates such that after controlling for these covariates, the potential outcomes are independent of treatment status (Eq. 10)

$$
\left(\mathrm{Y}_{1}, \mathrm{Y}_{0}\right) \perp \mathrm{D} \mid \mathrm{X}
$$

This assumption is also known as selection on observables, and it requires that all variables relevant to the probability of receiving treatment may be observed and included in X. This allows the untreated units to be used to construct an unbiased counterfactual for the treatment group.

The common support condition entails the existence of sufficient overlap in the characteristics of the treated and untreated units to find adequate matches (or a common support). When these two assumptions are satisfied, the treatment assignment is said to be strongly ignorable. Common support: for each value for $\mathrm{X}$, there is a positive probability of being both treated and untreated (Eq. 11).

$0<P(\mathrm{D}=1 \mid X)<1$

The assumption of common support ensures that there is sufficient overlap in the characteristics of treated and untreated units to find adequate matches. The procedure for estimating the impact of program can be divided into three steps: First, the samples of participants and nonparticipants should be pooled, and then participation $T$ should be estimated on all the observed covariates $\mathrm{X}$ in the data that are likely to determine participation. When one is interested only in comparing outcomes for those participating $(\mathrm{T}=1)$ with those not participating $(\mathrm{T}=0)$, this estimate could be constructed from a probit or logit model of program participation. Second, the region of common support needs to be defined where distributions of the propensity score for treatment and comparison group overlap. As mentioned earlier, some of the nonparticipant observations may have to be dropped because they fall outside the common support. Sampling bias may still occur, however, if the dropped non-participant observations are systematically different in terms of observed characteristics from the retained non-participant sample; these differences should be monitored carefully to help interpret the treatment effect.

For PSM to work, the treatment and comparison groups must be balanced in that similar propensity scores are based on similar observed X. The distributions of the treated group and the comparator must be similar, which is what balance implies. Formally, one needs to check if $\mathrm{P}^{\wedge}(\mathrm{X} \mid \mathrm{T}=1)=\mathrm{P}^{\wedge}(\mathrm{X} \mid \mathrm{T}=0)$. In the third step, different matching criteria could be used to assign participants to non- participants on the basis of the propensity score. According to Caliendo and Kopeinig (2008), there are steps in implementing PSM. These are estimation of the propensity scores using binary model, choosing a matching algorism, checking on common support condition, testing the matching quality and sensitivity analysis.

\section{Estimating Propensity Scores}

This study was employed the probit model to estimate propensity scores and selected variables would be included in the model. Because the matching procedure conditions on the propensity score but does not condition on individual covariates, one must check that the distribution of variables are 'balanced' across the adopter and non- adopter groups. Rosenbaum and Rubin (1985) recommend that standardized bias (SB) and $t$-test for differences be used to check matching quality. If the covariates $\mathrm{X}$ are randomly distributed across adopter and non-adopter groups, the value of the associated pseudo- $\mathrm{R}^{2}$ should be fairly low and likelihood ratio should also be insignificant.

\section{Choosing a Matching Algorithm}

The most commonly used matching algorithms, are nearest neighbour matching, radius matching, kernelbased matching, and caliper were employed to assess the impact of high yielding wheat varieties adoption on households' farm income. The nearest neighbour matching method matches each farmer from the adopter 
group with the farmer from the non-adopter group having the closest propensity score. Nearest neighbour matching faces the risk of bad matches if the closest neighbour is far away. This risk can be reduced by using a radius matching method, which imposes a maximum tolerance on the difference in propensity scores. However, some treated units might not be matched if the dimension of the neighbourhood (i.e. the radius) is too small to contain control units. The kernel-based matching method uses a weighted average of all farmers in the adopter group to construct a counterfactual. The major advantage of the kernel matching method is that it produces ATT estimates with lower variance since it utilizes greater information; its limitation is that some of the observations used may be poor matches.

\section{Checking overlap and common support}

Imposing common support condition ensures that any combination of characteristics observed in the treatment group can also be observed among the control group (Bryson et al., 2002). The common support region is the area which contains the minimum and maximum propensity scores of treatment and control groups of sample households, respectively. Comparing the incomparable must be avoided, i.e. only the subset of the comparison group that is comparable to the treatment group should be used in the analysis.

Hence, an important step is to check the overlap and the region of common support between treatment and comparison group. One means to determine the region of common support more precisely is by comparing the minima and maxima of the propensity score in both groups. The basic criterion of this approach is to remove all observations whose propensity score is smaller than the minimum and larger than the maximum in the opposite group. Observations which lie outside this region are discarded from analysis (Caliendo and Kopeinig, 2008). No matches can be made to estimate the average treatment effects on the ATT parameter when there is no overlap between the treatment and non-treatment groups.

\section{Testing the matching quality}

Since we do not condition on all covariates but on the propensity score, it has to be checked if the matching procedure is able to balance the distribution of the relevant variables in both the control and treatment group. The main purpose of the propensity score matching is not to perfectly predict selection into treatment but to balance all covariates. While differences in covariates are expected before matching, these should be avoided after matching. The primary purpose of the PSM is that it serves as a balancing method for covariates between the two groups. Consequently, the idea behind balancing tests is to check whether the propensity score is adequately balanced. In other words, a balancing test seeks to examine if at each value of the propensity score, a given characteristic has the same distribution for the treated and comparison groups. The basic idea of all approaches is to compare the situation before and after matching and check if there remain any differences after conditioning on the propensity score (Caliendo and Kopeinig, 2008). The crucial issue is to ensure whether the balancing condition is satisfied or not because it reduces the influence of confounding variables (Rosenbaum and Rubin, 1983; Dehejia and Wahba,
2002).

Sensitivity analysis

Recently checking the sensitivity of the estimated results becomes an increasingly important topic in the applied evaluation literatures (Caliendo and Kopeining, 2008). Matching method is based on the conditional independence or unconfoundedness assumption, which states that evaluator, should observe all variables simultaneously influencing the participation decision and outcome variables. This assumption is intrinsically non-testable because the data are uninformative about the distribution of the untreated outcome for treated units and vice versal (Becker and Caliendo, 2007). The estimation of treatment effects with matching estimators is based on the unconfoundedness or selection on observables assumption. However, if there are unobserved variables which affect assignment into treatment and the outcome variable simultaneously, a 'hidden bias' might arise (Rosenbaum, 2002). In other word, if treatment and outcomes are also influenced by unobservable characteristics, then CIA fails and the estimation of ATTs are biased. The size of the bias depends on the strength of the correlation between the unobservable factors, on the one hand, and treatment and outcomes, on the other.

\section{Definition and Measurement of Variables Outcome variable}

Farm income: It is continuous variable indicating the amount of annual farm income earned by households. It is an outcome variable measured in terms of ETB that generated in the year. The farm income obtained from both production of crops and livestock activities were considered because, farmers in the area could be undertaken mixed farming activities. It considered the share of income obtained from farming activities and it is acceptable to include every source that can generate income to household from crop production and livestock raising by smallholders (Tab. 1).

\section{Explanatory variables}

The independent variables of the study were those which were expected to have association with the adoption of agricultural technologies on basis of past research studies, based on the literature reviews and prior knowledge of the study area (Tab. 1).

\section{RESULTS AND DISCUSSION}

The study presents results explaining smallholder farmers' propensity of adoption of high yielding wheat varieties and its impact on farm income by smallholder farmers through the statistical analysis of descriptive tools and empirical results of econometric analysis.

\section{Descriptive Results}

Descriptive statistics were used to describe the socioeconomic and institutional characteristics of the households under considered in the study of high yielding wheat varieties adoption and its impact on farm income of smallholder farmers. The descriptive results revealed that treated households were significantly different from nontreated groups in many cases such as farm land holding size, family size, livestock ownership, frequency of extension visit, and educational level (Tab. 2). 
The treated groups did not make significant difference in terms of distance from market centre, distance to main road, farming experiences, access to credit services, sex of household head, off/non-farm income activities, and participation in local level organization with compared to non-treated (Tab. 2).

The survey data revealed that no significant difference is observable in the sex of household head since almost all of the respondents were male headed households. The treated groups were significantly distinguishable in terms of access to information. The survey result revealed that on average about 43.68 treated had chance to access available agricultural information while only 31.61 nontreated access to agricultural information. The chi-square test results show that access to information related to high yielding wheat varieties between the two groups was statistically significant at $1 \%$ significance level (Tab. 3).

However, in terms of participation in the formal organization, the mean difference between the two groups (treated and non-treated) was statistically insignificant; showing that there is no difference between the two groups of households (Tab. 3).

Impact of high yielding wheat varieties adoption on farm income

By employing the binary probit regression model, the important variables explaining propensity of participation in high yielding wheat varieties adoption were identified. The results showed that important explanatory variables which were hypothesized to affect participation in high yielding wheat varieties adoption was computed from propensity of adoption. The contributing of those variables on the dependent variable and could be those that sex of household, land holding size, tropical livestock unit, frequency of extension contacts, access to information, off/non-farm income, perceptions of farmers' toward attributes of high yielding wheat varieties, affiliation to organizations would ease participation in the adoption of high yielding wheat varieties.

Propensity score distribution of adopters and nonadopters

The estimation of predicted values of high yielding wheat varieties adoption (propensity scores) for all participant and non-participant households would be accomplished from the propensity of adoption. A common support condition should be imposed on the propensity score distributions of the households with and without the program (adoption of high yielding wheat varieties). After this, discarded observations whose predicted propensity scores fall outside the range of the common support region would be accomplished and at last sensitivity analysis should be done in order to check whether the hidden bias affects the estimated ATT or not.

On the basis of estimated propensity score of adopters and non-adopters households, the distribution of the propensity score for each household included in the treated and control groups were computed to identify the existence of a common support.

Table 1 Summary of covariate used in the study

\begin{tabular}{ll}
\hline Variables & Measurements \\
\hline Sex of household head & Dummy; 1=Male, 0=Female \\
Family size & Continuous, total no. of family members \\
Educational level & Continuous, years of schooling \\
Farming experience & Continuous, years of farming \\
Land holding of household & Continuous, hectares \\
Livestock holding unit (tlu) & Continuous, values \\
Distance from market center & Continuous, kilometers \\
Access to credit & Dummy; yes/not \\
Distance to main road & Continuous; kilometers \\
Frequency of extension contacts & Continuous; no. of days \\
Non-farm income & Continuous (log); ETB \\
Farmers' perception of HYV of wheat attributes Dummy/ Ordinal variable \\
Farmer's affiliation to organizations & Dummy; yes/not \\
\hline
\end{tabular}

Table 2 Summary statistics for continuous covariates (variables)

\begin{tabular}{lcccc}
\hline Descriptions & $\begin{array}{c}\text { Treated } \\
\text { Mean }\end{array}$ & $\begin{array}{c}\text { Non-treated } \\
\text { Mean }\end{array}$ & $\begin{array}{c}\text { Total Sample } \\
\text { Mean }\end{array}$ & T-test value \\
\hline Land holding size (ha) & 1.83 & 1.16 & 1.50 & $-5.114^{* * *}$ \\
Total livestock unit (tlu) & 4.29 & 1.46 & 2.88 & $-6.803^{* * *}$ \\
Educational level (years) & 1.99 & 1.49 & 1.74 & $-1.517^{*}$ \\
Distance from market center (km) & 4.20 & 4.37 & 4.29 & 0.447 \\
Distance to main road (km) & 2.83 & 2.77 & 2.80 & -0.145 \\
Farming experiences (years) & 25.39 & 23.48 & 24.44 & -1.165 \\
Family size (number) & 7.59 & 6.72 & 7.16 & $-2.100^{* *}$ \\
Off/non-farm income (ETB) & 3.26 & 3.25 & 3.26 & -0.024 \\
Frequency of extension contact (days) & 20.48 & 12.97 & 16.72 & $-3.263^{* * *}$ \\
\hline
\end{tabular}

*, **, and *** indicates significant at $10 \%, 5 \%$ and $1 \%$ significance levels, respectively.

Source: Own survey (2015) 
Table 3 Summary statistics for dummy/discrete covariates (variables)

\begin{tabular}{|c|c|c|c|c|}
\hline Descriptions & $\begin{array}{l}\text { Treated } \\
\text { Mean }\end{array}$ & $\begin{array}{l}\text { Non-treated } \\
\text { Mean }\end{array}$ & $\begin{array}{l}\text { Total Sample } \\
\text { Mean }\end{array}$ & $\chi^{2}$-value \\
\hline \multicolumn{5}{|c|}{ Access to credit services } \\
\hline Yes & 3.45 & 2.87 & 6.45 & 0.755 \\
\hline No & 46.55 & 47.13 & 93.68 & \\
\hline \multicolumn{5}{|c|}{ Access to information } \\
\hline Yes & 43.68 & 31.61 & 75.29 & $13.622 * * *$ \\
\hline No & 18.39 & 6.32 & 24.71 & \\
\hline \multicolumn{5}{|c|}{ Affiliation to organizations } \\
\hline Yes & 48.28 & 47.13 & 95.40 & 0.469 \\
\hline No & 1.72 & 2.87 & 4.60 & \\
\hline \multicolumn{5}{|c|}{ Sex of household } \\
\hline Male & 47.13 & 47.70 & 94.83 & 0.732 \\
\hline Female & 2.87 & 2.30 & 5.17 & \\
\hline
\end{tabular}

Figure 1 portrays distribution of the sample households with respect to the estimated propensity scores. Moreover, the Figure 1 portray the kernel density distributions of the propensity score of the sample households' (both treated and untreated groups) that the distribution for all households is relatively near to normal distribution. In case of treatment (adopters) households, most of them are partly found in the center and partly in the right side of the distribution, whereas most of the control (untreated) households are found in the left side of the distribution.

Generally, the figure 1 shows that there is wide area in which the propensity score of treated is similar to those of control groups. The figure 1 portray that there was a considerable overlap or common support between the two groups of respondents (treated and control) of smallholders. Furthermore, it depict that there is high chance of getting good matches and large number of matched sample size from the distribution as the propensity score distribution is skewed to the left for treated and right for untreated. This is based on the minima and maxima approach of common support region identification (Caliendo and Kopeinig, 2008).

\section{Matching of treated and control groups}

Matching of treated and control households was carried out to determine the common support region. The basic criterion for determining the common support region is to discard all observations whose propensity score is smaller than the minimum propensity scores of adopters (treated) and larger than the maximum of the (control group) nonadopters (Caliendo and Kopeining, 2008). That is, excluding all observations out of the overlapping region.

The common support assumption is satisfied in the region of [0.0698-0.9687] for sample households (Tab. 4). This means that households with estimated propensity scores less than 0.0698 and greater than 0.9687 are not considered in the matching undertakings. As a result of this restriction, 26 sample households (11 treated and 15 control sample households) were discarded and 148 sample households were identified to be considered in the estimation process. The Figure 2 portrays the distribution of estimated propensity scores, with and without the imposition of the common support condition, for treated and untreated sample households, respectively. The distribution of estimated propensity scores with the imposition of the common support condition, most of the treated households have propensity score a round 0.9 while majority of the untreated households have propensity score less than 0.1 (Fig. 2, Fig. 3).

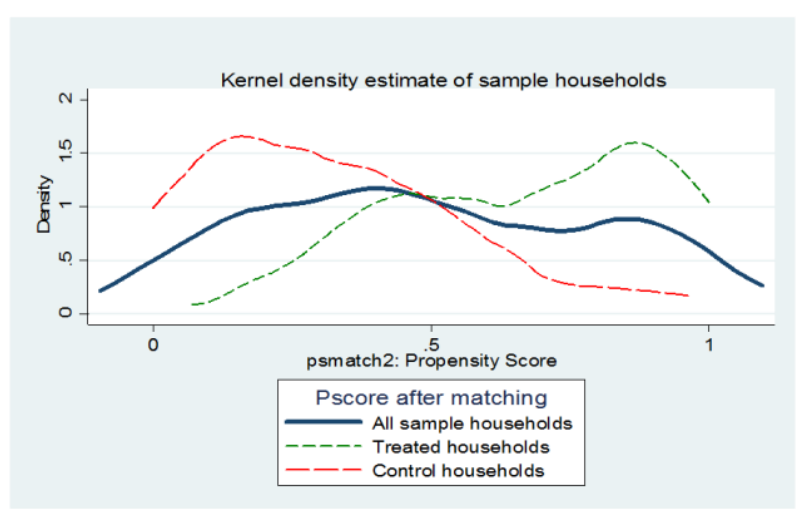

Figure 1 Kernel density of propensity score distribution for sample households

Table 4 Distribution of estimated propensity scores for sample households

\begin{tabular}{lcccc}
\hline Group & Mean & Std.Dev & Minimum & Maximum \\
\hline $\begin{array}{l}\text { Treated } \\
\text { households }\end{array}$ & 0.6748 & 0.2411 & 0.0698 & 0.9999 \\
$\begin{array}{l}\text { Untreated } \\
\text { households }\end{array}$ & 0.3179 & 0.2335 & 0.0001 & 0.9687 \\
$\begin{array}{l}\text { Total } \\
\text { households }\end{array}$ & 0.4963 & 0.2966 & 0.0001 & 0.9999 \\
\hline Source: Own survey (2015) & & \\
\hline
\end{tabular}

Source: Own survey (2015)

\section{Choice of matching Algorithm}

Choice of matching al gorithm was carried out from kernel bandwidth, nearest neighbour matching, radius caliper methods. The choice of estimator based on three criteria; namely, balancing test (number of insignificant variables), pseudo $\mathrm{R}^{2}$ and number of matched sample size. Likewise, a matching estimator which balances more independent 
variables, has low pseudo $\mathrm{R}^{2}$ value and results in large matched sample size was chosen as being the best estimator of the data. Accordingly, nearest neighbour matching method (NNM) with propensity score closest to (3) was found to be the best estimator for the data at hand on the farm income of sample households. Relatively, this estimator (NNM 3) resulted in lowest pseudo $\mathrm{R}^{2}(0.030)$ value, well balanced covariates, and large number of matched sample size that were 76 treated and 72 untreated with a total of 148 sample households by discarding only 26 unmatched (off support) households (Tab. 5).

Moreover, in what follows estimation results and discussion are the direct outcomes of the nearest neighbour matching algorithm based on propensity score closest to 3. Therefore, estimate of ATT for sample households would be proceeded.

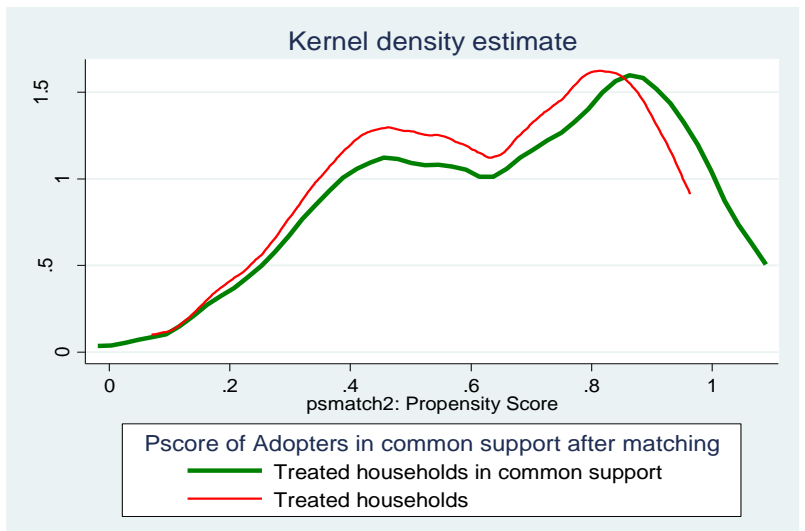

Figure 2 Kernel density of propensity scores of treated households

Testing the balance of propensity score and covariates After choosing the best performing matching algorithm (nearest neighbour matching) the next task is to check the balancing of propensity score and covariates. The t-test suggests that differences in household characteristics between the treatment and control groups are jointly insignificant both before and after matching. The main purpose of the estimation of propensity score is to balance the distributions of relevant variables in both treatment and control groups but not to obtain a precise prediction of selection into treatment.

Table 6 displays results of balancing test of the covariate by comparing the before and after matching algorithm significant differences. Before matching, there were some variables which were significantly different for the two groups of respondents. However, after matching some of these significant covariates were conditioned to be insignificant which indicates that the balance that was made in terms of the covariates between treatments and untreated.

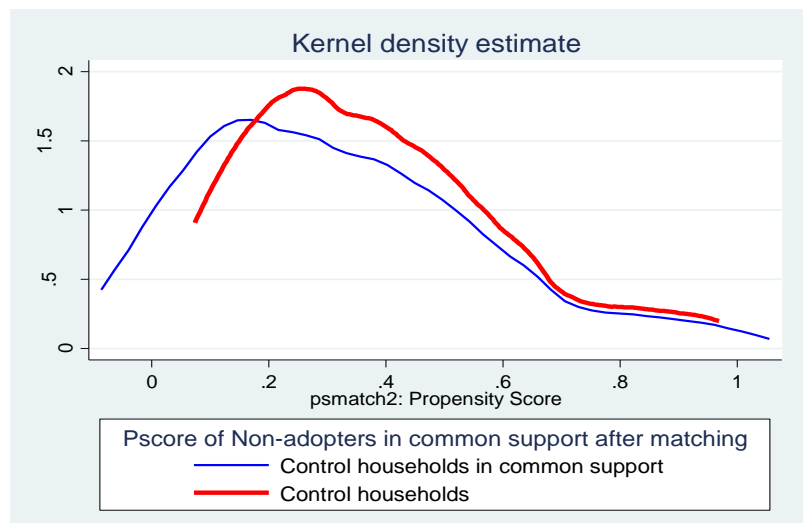

Figure 3 Kernel density of propensity scores of nontreated household

Table 5 Performance of matching estimators for sample households

\begin{tabular}{lccc}
\hline Matching estimator & $\begin{array}{l}\text { Performance } \\
\text { Balancing test }\end{array}$ & & Pseudo R ${ }^{2}$ \\
& $\begin{array}{l}\text { Matched } \\
\text { sample size }\end{array}$ \\
\hline Kernel Matching & 8 & 0.073 & 85 \\
Bandwidth (0.01) & 7 & 0.059 & 148 \\
Bandwidth (0.1) & 7 & 0.039 & 148 \\
Bandwidth (0.25) & 7 & 0.070 & 148 \\
Bandwidth (0.5) & & & \\
Nearest Neighbour Match (NNM) & 5 & 0.118 & 148 \\
Neighbour (1) & 7 & 0.058 & 148 \\
Neighbour (2) & 7 & 0.030 & 148 \\
Neighbour (3) & 7 & 0.034 & 148 \\
Neighbour (4) & 7 & 0.047 & 148 \\
Neighbour (5) & & & 85 \\
Radius Caliper Matching (RCM) & 7 & 0.078 & 148 \\
Radius (0.01) & 7 & 0.055 & 148 \\
Radius (0.1) & 7 & 0.038 & 148 \\
Radius (0.25) & 6 & 0.114 & \\
Radius (0.5) & & & \\
\hline
\end{tabular}

* Indicate number of insignificant variables

Source: Own survey result (2015) 
Table 6 Propensity score and covariate balance

\begin{tabular}{|c|c|c|c|c|c|c|}
\hline \multirow[t]{2}{*}{ Variables } & \multicolumn{3}{|c|}{ Before matching (174) } & \multicolumn{3}{|c|}{ After matching (148) } \\
\hline & $\begin{array}{l}\text { Treated } \\
\text { (87) }\end{array}$ & $\begin{array}{l}\text { Control } \\
\text { (87) }\end{array}$ & T-value & $\begin{array}{l}\text { Treated } \\
\text { (76) }\end{array}$ & $\begin{array}{l}\text { Control } \\
\text { (72) }\end{array}$ & T-value \\
\hline Sex of households head & 0.94 & 0.95 & 0.34 & 0.93 & 0.96 & 0.39 \\
\hline Farming experiences & 25.39 & 23.48 & -1.17 & 25.51 & 25.86 & 0.85 \\
\hline Educational level & 1.99 & 1.49 & $-1.52 *$ & 1.87 & 1.71 & 0.65 \\
\hline Distance to main road & 2.83 & 2.77 & -0.14 & 2.75 & 2.23 & 0.18 \\
\hline Family size & 7.60 & 6.72 & $-2.10 * *$ & 7.46 & 7.54 & 0.85 \\
\hline Land holding size & 1.79 & 1.09 & $-5.11 * * *$ & 1.61 & 1.57 & 0.82 \\
\hline Tropical livestock unit & 4.29 & 1.46 & $-6.80 * * *$ & 3.55 & 3.82 & 0.57 \\
\hline Access to credit & 0.07 & 0.06 & -0.31 & 0.08 & 0.05 & 0.52 \\
\hline Frequency of extension contacts & 20.48 & 12.97 & $-3.26 * * *$ & 18.21 & 18.98 & 0.74 \\
\hline Access to information & 0.87 & 0.63 & $-3.82 * * *$ & 0.87 & 0.90 & 0.45 \\
\hline Off-farm income & 3.26 & 3.25 & -0.02 & 3.30 & 2.17 & 0.07 \\
\hline Perception of households' & 1.11 & 1.69 & $7.22 * * *$ & 0.96 & 1 & 0.08 \\
\hline Affiliation to organizations & 0.97 & 0.94 & -0.72 & 0.96 & 1 & 0.08 \\
\hline
\end{tabular}

$*, * *$ and $* * *$ indicates significant at $10 \%, 5 \%$ and $1 \%$ significance levels, respectively.

Source: Own survey result (2015)

The low pseudo- $\mathrm{R}^{2}$ and the insignificant likelihood ratio tests support the hypothesis that both groups have the same distribution in covariates after matching (Tab. 7). The result clearly show that the matching technique is capable to balance the characteristics in the treated and control comparison groups. It was used to evaluate the effect of the adopting high yielding wheat varieties among the groups having similar observed characteristics that compare observed outcome for treated with those of a comparison group sharing a common support.

Table 7 Tests for the joint significance

\begin{tabular}{lccr}
\hline Sample & Pseudo R & Wald/LR chi & Prob $>$ chi $^{2}$ \\
\hline Unmatched & 0.30 & 51.05 & 0.0000 \\
Matched & 0.03 & 6.08 & 0.868 \\
\hline
\end{tabular}

Source: Own survey result (2015)

All of the tests suggest that the matching algorithm chosen is relatively the best for the data at hand. Thus, this study has chosen NNM (3) matching method as the best estimator and then proceed to run the ATT estimation with this best choice estimator.

\section{Treatment effect on the treated (ATT)}

Average treatment effect (ATT) estimation using nearest neighbour matching method with closest (3) which summarizes the outcome variables that is farm income of adopters and non-adopters (Tab. 8). It is clear that the average treatment effect on the treated (ATT) of farm income of treated groups earned 9.9736 which is equal to

21452.28 ETB while controls (untreated) groups earned the farm income of 9.3184 which is equivalent to 11141.14 ETB, indicating the effective level of significance. That is the average farm income of the treatments is greater than average farmincome of matched (control) groups. The result indicates that the propensity of adoption decision of high yielding wheat varieties has resulted in a positive and statistically significant difference between adopters and non-adopters in terms of farm income by smallholder households.

In general, the adoption decision of households for high yielding wheat varieties has generated about $9 \%$ increase in farm income of treated households over control groups. Accordingly, it is possible to conclude that the impact analysis of households on farm income has positive effect on the smallholder households of the study area. Overall, the results are in agreement with the findings of other researchers on the impacts of agricultural technology adoption by Mendole (2007), Kassie et al. (2010), Solomon (2010), Wu, et al. (2010) and Tsegaye and Bekele (2012).

\section{Sensitivity of the estimated average treatment effects (ATT)}

Matching estimators work under the assumption that a convincing source of exogenous variation of treatment assignment does not exist. Based on this principle, sensitivity analysis is tested to check whether unobserved covariates have effect on the result by creating biases or not.

Table 8 Estimate of average treatment effects on farm income of smallholder household

\begin{tabular}{lcccccc}
\hline Outcome variable & Sample & Treated & Controls & Difference & S.E & T-stat \\
\hline \multirow{3}{*}{ Farm income $(\log )$} & Unmatched & 10.1076 & 8.5687 & 1.5389 & 0.2065 & 7.45 \\
& ATT & 9.9736 & 9.3184 & 0.6552 & 0.4178 & $1.57 * * *$ \\
& ATU & 8.6519 & 9.5330 & 0.8811 & & \\
\hline
\end{tabular}

\footnotetext{
*** indicate significant at $1 \%$ significance level.
}

Source: Own survey (2015) 
Furthermore, after ATT is found, it is vital to test whether the estimated ATT is effective or not. According to Dehejia (2002), sensitivity analysis is the final diagnostic that performed to check the sensitivity of the estimated treatment effect to small changes in the specification of the propensity score; this is a useful diagnostic on the quality of the comparison group.

Table 9 Sensitivity analysis of the estimated ATT

\begin{tabular}{lcc}
\hline Gamma & $\sigma^{+}$ & $\sigma^{-}$ \\
\hline 1 & 0 & 0 \\
1.25 & 0 & 0 \\
1.5 & $1.3 \mathrm{e}-14$ & 0 \\
1.75 & $8.9 \mathrm{e}-13$ & 0 \\
2 & $2.1 \mathrm{e}-11$ & 0 \\
2.25 & $2.5 \mathrm{e}-10$ & 0 \\
2.5 & $1.8 \mathrm{e}-09$ & 0 \\
2.75 & $9.3 \mathrm{e}-09$ & 0 \\
3 & $3.6 \mathrm{e}-08$ & 0 \\
3.25 & $1.1 \mathrm{e}-07$ & 0 \\
3.5 & $3.1 \mathrm{e}-07$ & 0 \\
3.75 & $7.3 \mathrm{e}-07$ & 0 \\
4 & $1.6 \mathrm{e}-06$ & 0
\end{tabular}

Source: Own survey estimation (2015)

Moreover, sensitivity analysis was undertaken to detect the identification of conditional independence assumption (CIA) and was satisfactory or affected by the confounder. This indicates the estimated ATT is robust to specific failure of the CIA. Table 9 revealed the sensitivity analysis of the outcome ATT values of farm income to the confounders. The significance level is unaffected even if the gamma values are relaxed in any desirable level, shows that ATT is insensitive to external change (Tab.9). Therefore, the CIA remain to be significant and the results were not sensitive to the confounders and there are no external cofounders (variables) which affect the result calculated for ATT already.

\section{CONCLUSIONS AND POLICY IMPLICATIONS}

\section{Summary and Conclusions}

In this study, the impact of high yielding wheat varieties due to interventions in Mao-Komo special district, Western Ethiopia, has been assessed using cross sectional data collected from small-holders. To estimate the effect of high yielding wheat varieties adoption on farm income of households the propensity score matching techniques was utilized. The adoption of high yielding wheat varieties has positive effect on the treated households for improving their income thereby fostering the economic growth of the smallholders.

The impact of adopting high yielding wheat varieties on farm income of smallholders' analysed based on sample of matched treated and control groups. A propensity score matching approach was used to compare adopter households with non-adopters in terms of farm income which is measured in Ethiopian birr. From the nearest neighbour matching method with propensity score closest to (3), the estimated of ATT found that adoption of high yielding wheat varieties had positive impact on treated farmers on farm income of smallholders. That means as the farmers adopt and practice the cultivation of high yielding wheat varieties indicating positive outcome on the adopters' on farm income obtained. The treated sample households were found to have a better income difference than the untreated (control group) sample households. The adoption decision of households for high yielding wheat varieties has generated about $9 \%$ increase in farm income of treated over control groups. Therefore, the adoption of high yielding wheat varieties was found to have a positive impact on the adopters in terms of farm income.

\section{Policy Implications}

Based on the result discussed earlier, the following policy recommendations can be drawn. Those households who could use the high yielding wheat varieties improve their farm income levels. Hence, scaling up the best practices of the adopters to other farmers can be considered as one option to enhance farm income generation of smallholder farmers in the area while introducing new practices and technologies is another option.

\section{Acknowledgment}

My deep sense of appreciation and heartfelt thanks goes to Ethiopian Institute of Agricultural Research (EIAR) and Building Ethiopian Research Capacity in Economics and Agribusiness through Global Development Network (BERCEA, GDN) Project of Haramaya University, providing funding for this research and other logistic supports. My extended gratitude goes to enumerators for their support in data collection, different individuals for technical support and selected rural village farmers for their cooperation during data collection.

\section{REFERENCES}

ADEKAMBI, S. A., DIAGNE, A. F., SIMTOWE, P. and BIAOU, G. (2009). The impact of agricultural technology adoption on poverty: The case of Nerica rice varieties in Benin. Contributed paper prepared for presentation at the International Association of Agricultural Economists' conference, 16-22 August 2009. Beijing, China. https://ageconsearch.umn.edu/bitstream/51645/2/473.pdf BAKER, J.L. (2000). Evaluating the impact of development projects on poverty: A handbook for Practitioners. Washington D.C. World Bank. http://documents.worldbank.org/curated/en/76234146827 8363048/

BECKER, S. O. AND ICHINO, A. (2002). Estimation of average treatment effects based on Propensity Scores. The Stata Journal, 2 (4): 1-19.

BECKER, S.O. and CALIENDO, M. (2007). Sensitivity Analysis for Average Treatment Effects. The Stata Journal, 7 (1): 71-83.

BRYSON, A., DORSETT, R. and PURDON, S. (2002). The use of Propensity Score Matching in the Evaluation of Labour Market Policies, Working Paper No. 4. Department for Work and Pensions. http://eprints.1se.ac.uk/4993/

CALIENDO, M. and KOPEINIG, S. (2008). Some practical guidance for the implementation of propensity 
score matching, IZA Discussion Paper No. 1588. University of Cologne. http://ftp.iza.org/dp1588.pdf CSA (Central Statistical Agency). (2007). Summary and Statistical Report of the 2007 population and housing census. Addis Ababa, Ethiopia.

DEHEJIA, R. H. and WAHBA, S. (2002). Propensity score matching methods for non- experimental causal studies. The Review of Economics and Statistics, 84 (1):151-161.

https://doi.org/10.1162/003465302317331982

DIXON, J., NALLEY, L., KOSINA, P., LA ROVERE, R., HELLIN, J. and AQUINO, P. (2006). Adoption and Economic Impact of Improved Wheat Varieties in the Developing World. Journal of Agricultural Science, 144 (489): 489-502.

https://repository.cimmyt.org/handle/10883/2121

DOROSH, P. and RASHID, S. (2013). Food and Agriculture in Ethiopia: Progress and Policy Challenges. University of Pennsylvania Press. Philadelphia, USA. DOI: http://doi.org/10.18352/ijc.448

EZEMENARI, K., RUDQVIST, A. and SUBBARAO, K. (1999). Impact Evaluation: A Note on Concepts and Methods, Poverty Reduction and Economic Management Network, World Bank.

FAO (Food and Agriculture Organization of the United Nations). (2009). How to feed the world in 2050. http://www.fao.org/fileadmin/templates/wsfs/docs/expert paper/How to Feed the World in 2050.pdf

FOSTER, E. (2003). Propensity score matching. An illustrative analysis of dose response. Lippincott Williams and Wilkins, Inc. Journal of Medical Care, 41 (10):11831192. DOI: 10.1097/01.MLR.0000089629.62884.22 HEINRICH, C., MAFFIOLI, A. and VÁZQUEZ, G. (2010). A Primer for Applying Propensity Score Matching: Impact-Evaluation Guidelines. Inter-American Development

Bank.

https://publications.iadb.org/handle/11319/1681

KATHLEEN, O. 2010. Measuring the Impact of Microfinance. Grameen Foundation Publication Series. PP 7. https://grameenfoundation.org/resource/measuringimpact-microfinance

MENALE KASSIE, BEKELE SHIFERAW and MURICHO, G. (2011). Agricultural technology, crop income, and poverty alleviation in Uganda. World Development, 39: 1784-1795. https://doi.org/10.1016/j.worlddev.2011.04.023

MENALE KASSIE, BEKELE SHIFERAW, MMBANDO, F. and MURICHO, G. (2012). Plot and household level determinants of sustainable agricultural practices in rural Tanzania. Environment for Development, Discussion Paper Series EfD DP 12-20. MERGA CHALLA and URGESSA TILAHUN. (2014). Determinants and Impacts of Modern Agricultural Technology Adoption in West Wollega: The Case of Gulliso District. Journal of Biology, Agriculture and Healthcare,

https://www.iiste.org/Journals/index.php/JBAH/article/vi ew/15700

OMOTO, W. (2003). Impact assessment of urban agriculture research and development in Nairobi, Kenya. $\underline{\text { http://erepository.uonbi.ac.ke:8080/handle/123456789/32 }}$ $\underline{37}$
RAVALLION, M. (2005). Evaluating anti-poverty programs: Policy research working paper 3625, World Bank, Washington D.C. http://documents.worldbank.org/curated/en/10476146831 5569641/pdf/wps3625.pdf

ROSENBAUM, P.R. and RUBIN, D.B. (1983). The Central Role of the Propensity Score in Observational Studies for Causal effects. Biometrika, 70 (1): 41-55. DOI: https://doi.org/10.1093/biomet/70.1.41

ROVER, T. and DIXON, R. (2007). Operational guidelines for assessing the impact of agricultural research on livelihoods. Good practices from CIMMYT. Mexico. http://purl.umn.edu/56180

SOLOMON ASFAW. (2010). Estimating Welfare Effect of Modern Agricultural Technologies: A MicroPerspective from Tanzania and Ethiopia, International Crops Research Institute for the Semi-Arid Tropics (ICRISAT). Nairobi, Kenya. http://www.chronicpoverty.org/uploads/publication_files lasfaw agricultural technologies.pdf

SOLOMON ASFAW and BEKELE SHIFERAW. (2010). Agricultural Technology Adoption and Rural Poverty: Application of an Endogenous Switching Regression for Selected East African Countries. Poster presented at the Joint 3rd African Association of Agricultural Economists (AAAE) and 48th Agricultural Economists Association of South Africa (AEASA) Conference, Cape Town, South Africa. https://ideas.repec.org/p/ags/aaae10/97049.html SOLOMON TIRUNEH. (2012). Impact of Improved Barley Scale Up/Out Program on Household Food Security in Meket District, North Eastern Ethiopia M.Sc. thesis Haramaya University.

SOLOMON ASFAW, MENALE KASSIE, SIMTOWE, F. and LIPPER, L. (2012). Poverty reduction effects of agricultural technology adoption: A micro-evidence from rural Tanzania. Journal of Development Studies, 48 (9):1288-1305. DOI: 10.1080/00220388.2012.671475

TSEGAYE MULUGETA and BEKELE HUNDIE. (2012). Impacts of adoption of improved wheat technologies on households' food consumption in Southeastern Ethiopia. Selected Poster prepared for presentation at the International Association of Agricultural Economists (IAAE) Triennial Conference, 18-24 August 2012. Foz do Iguaçu, Brazil. http://purl.umn.edu/126766

UNDP (United Nations Development Program). (2014). Ethiopia: Quarterly Economic Brief. Third Quarter, 2014. Addis Ababa, Ethiopia.

WU, H., DING, S., PANDEY, S. and TAO, D. (2010). Assessing the impact of agricultural technology adoption on farmers' well-being in Rural China. Asian Economic Journal, $24 \quad$ (2): $141-160 . \quad$ DOI: https://doi.org/10.1111/j.1467-8381.2010.02033.x 